\title{
狭い場所から開放されたときの魚群の行動
}

草下孝 也

(1961 年 3 月 14 日受理)

\section{AN EXPERIMENTAL STUDY REGARDING FISH BEHAVIOR AT THE TIME WHEN FISHES WERE ALLOWED TO ESCAPE FROM A NARROW PLACE}

\author{
Takaya KusaKa*
}

This is an important problem when considered with practical fisheries, especially to find out the movements of fishes inside the net when they are gathered. Many investigations had been carried out regarding this problem (See references).

For this experiment, Japanese Killifish Aplocheilus latipes was used. The equipments were 5 tanks of different sizes and two cylinders of diameter $13 \mathrm{~cm}$ of which one was transparent made out of celluloid and the other was painted white inside so that the fishes were not allowed to see the environment. About 15 individuals were liberated in each cylinder and it was lifted above after some times. The time lapses from then to when they moved out were observed (Tables $3 \sim 5$ ). Staying times were particularly to find out the difference of effects between the transparent cylinder and the cylinder painted white inside.

The result obtained is as follows: ....

Staying time, the time between lifting up of cylinder and swimming out of fish.

\begin{tabular}{l|c|c|c}
\hline \multicolumn{1}{c|}{ Cylinder used } & \multicolumn{3}{|c}{ Keeping time inside cylinder } \\
\hline $\begin{array}{l}\text { Transparent celluloid } \\
\text { White painted }\end{array}$ & $\begin{array}{l}\text { 1 minute } \\
\text { about } 14 \text { seconds }\end{array}$ & $\begin{array}{l}\text { about } 35 \text { seconds } \\
\text { about } 8 \text { seconds }\end{array}$ & $\begin{array}{l}\text { less than } 10 \text { seconds } \\
\text { les minutes } \\
10 \sim 15 \text { seconds }\end{array}$ \\
\hline
\end{tabular}

In the case of the transparent cylinder, it was observed that when the keeping time was increased, the staying time also increased.

So it may be suggested that the fishes get more well accommodated the transparent cylinder than the painted cylinder. On the other hand, in the case of the painted cylinder even if the keeping time was increased, the staying time was found to be increased only by a few seconds. The sudden outburst of the fish that are kept in the painted cylinder, could be the result of the stimulus produced when they are allowed to escape suddenly from an enclosed place to a more open space.

緒言

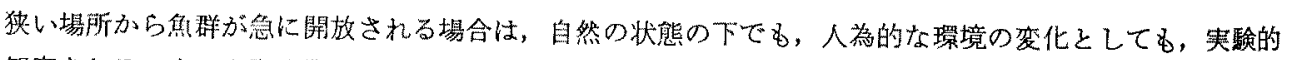

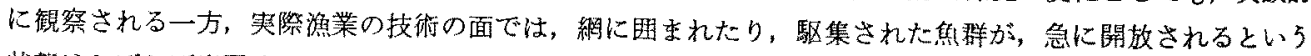

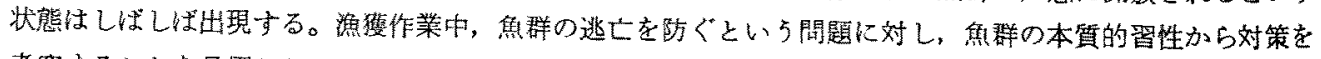
考究することを目標として、この实験兴進めた。

*東京大学㩊学部 (Fish. Dep., Fac. Agr., Tokyo Univ., Bunkyo-ku, Tokyo). 
すなわち，狭い容器内に閉じこめられていた魚群が，その容器が突然取り除かれて開放された場合に，魚 群の活動がそれによつてどのように影響されるか，また，それをどの上うに説明することがでさるかについ て考究した。畄をガラス容器などに入れたとき，始めは頭部を壁にぶつけて，上下を右炕激しい運動をする が、やがて，次第に平常な状態にもどり，あたかも容器内の生活に澒応したかのように観察される。

これに関連して，Triplett ${ }^{12}$ は Perchを用いて実験を行なつた。すなわら，水槽に Perch を入れ，さら にそこへ，その天然解料となる Minnow をガラス壁で分離して入れた。Perch は始めは慨に向つて繰返し 突進したが，やがて Minnow を捕える企てを放菓することを覚光た。

この訓練が完全になつた後にガラス壁を除いたところが，Perch は Minnow のなが自由に泳ぎ回り， Minnow を捕食することは抑制された。

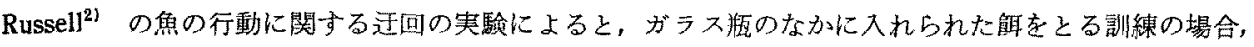
はじめはガラス壁に突進してなかの慨をとろうとするが，偶然に瓶の入口から入つて，なかの䬣をとること

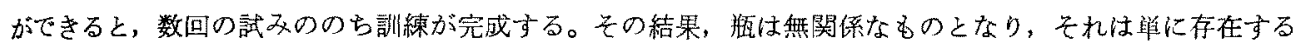
のみになると述べている。

Spooner" の过回に関する実験でもほぼ同様なことが立証されている。また，がラス壁に黑い線が描かれ ると学習は速やかに完成され，魚の動きも非常に意味をもつて異なつてくる。学習は以前に経跧されなかつ た，または発見されなかつた外部的位置に扎けるなんらかの一般的な関㐿を并別することに因る。その環境 をより明瞭に涺察，または升別することをもつて，魚はまるむつとも効果的な反応示すことが可能である と記述している。

\section{実 験 方 法}

実験材料にはメダカ Aplocheilus latipes を使用した。(Table 1) 実験に使用した水槽は Table 2.の ようである。透明なせルロイド製と内側を白色塗装した直径 $7.5 \mathrm{~cm}$ ，高さ $13 \mathrm{~cm}$ の2䇢の円筒を用意し， そのいずれか一つを水槽のなかに置き，そのなかにメダカを 15 尾前後入れて,一定時間放置した後, 円筒を静 がにとんと水滴を落さず上方に引揚げる。魚はしぱらくためらつたのち，その場から泳ぎ去る。この停滞 している時間が，円筒と留置時間によつて買なつてくるのを観察㭲討した。円簡を置く水槽の底には円を描 いて括き，その月から魯群の全部および大半が涾ぎ出るまでの時間を記録した。実験鼠は観察ごとに变えて 同じ材料をつづけて用いないよ5にした。寒験は室内で, 自然光を逅蔽し, $100 \mathrm{~W}$ 䉓球を水面上 $50 \mathrm{~cm}$ に

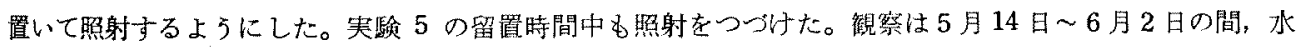
温は $18.5 \sim 22.3^{\circ} \mathrm{C}$ の範团で行なつた。

Table 1. Fish materials used for the experiment.

\begin{tabular}{c|c|cc}
\hline $\begin{array}{c}\text { Materials } \\
\text { mark }\end{array}$ & $\begin{array}{c}\text { Received } \\
\text { date }\end{array}$ & \multicolumn{2}{|c}{ Fish size } \\
\cline { 2 - 4 } & Total length & Average \\
\hline $\mathrm{S}$ & - & $13 \sim 23 \mathrm{~mm}$ & $19.2 \mathrm{~mm}$ \\
$\mathrm{M}$ & May 12 & $19 \sim 28 " \prime$ & $24.5 \prime \prime$ \\
$\mathrm{L}$ & May 15 & $20 \sim 34 "$ & $26.4 \prime \prime$ \\
\hline
\end{tabular}

Table 2. Tanks used for the experiment.

\begin{tabular}{c|c|rrr}
\hline $\begin{array}{c}\text { Tank } \\
\text { mark }\end{array}$ & Kind of tanks & \multicolumn{3}{|c}{ Sizes } \\
& Length Wide Depth \\
\hline A & Cubic glassware & 22 & 22 & 30 \\
B & Glazed the four sides & 45 & 30 & 37 \\
C & White enameled pan & 36 & 24 & 8.5 \\
D & Wooden, inside & 30 & 22 & 6.5 \\
E & plating celluloid & 121 & 121 & 24 \\
\hline
\end{tabular}

\section{観 察 結 果}

实験 1. 透明円筒に 1 分間留置してから開放した場合

結果は 10 回の綝返し観察中，1例を除き，全魚群が泳ぎ出るまでの時間は 13.5 19.8 秒 (平均 17.0秒)， 
1.2 尾を残して大部分が泳ぎ去るまでの時間は 8.0 19.2 秒（平均 14.4 秒）であつた。(Table 3)

実験 2、透明円筒に 1 時間留置してから開放した場合

結果は繰返し 10 回中，速やかと泳ぎ出した 2 例（13 および 20 秒）を除き,だいたい30 秒以上を要 し，大半が泳ざ出すに要した時間は 13〜60 秒（平均 35.3 秒）で，明らかに央騟 1。より，長時間を要す ることが認められた。(Table 3)

実験 3. 白色円筒に1 分間留圈してから開放した場合

結果は 1 例 (39.2 秒) を除き速やかに円外人泳ざ出し，大半が泳ぎ出すまでの時間は 7.5 10.9 秒（平 均 8.6 秒) であつた。(Table 4).

実験 4. 白色円简に 1 時間留置してから開放した場合

結果は 1 例 (66 秒) を除き，円外に泳ぎ出すのが速く，大半が涾さ出すをでの時間は 4.2 30 秒（平均

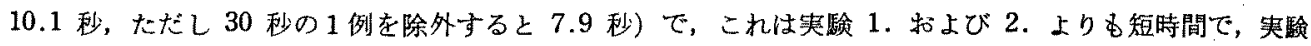
3.とは大差がない。(Table 4)

Table 3. The result on the case using the transparent celluloid cylinder.

Experiment 1. 1 minute keeping inside cylinder

\begin{tabular}{|c|c|c|c|c|c|c|c|}
\hline \multicolumn{2}{|c|}{ Observation } & \multicolumn{2}{|c|}{ Time lapse swim out from the place } & \multirow{2}{*}{$\begin{array}{c}\text { Individual } \\
\text { number } \\
\text { used }\end{array}$} & \multirow{2}{*}{$\begin{array}{c}\text { Water } \\
\text { temperature }\end{array}$} & \multirow{2}{*}{$\begin{array}{c}\text { Materials } \\
\text { used }\end{array}$} & \multirow{2}{*}{$\begin{array}{l}\text { Tank } \\
\text { used }\end{array}$} \\
\hline Number & Date & $\begin{array}{c}\text { All } \\
\text { individuals }\end{array}$ & Remarks & & & & \\
\hline 1 & May 14 & $\begin{array}{l}\text { seconds } \\
19.2\end{array}$ & Continuously swim out & 14 & 18.5 & $\mathbf{S}$ & A \\
\hline 2 & $"$ & 19.8 & $14 \mathrm{sec}$. remain 2 ind. & 15 & $"$ & $" \prime$ & $"$ \\
\hline 3 & " & 44.3 & 17 sec. remain 1 ind. & $"$ & " & $\mathbf{M}$ & $\mathrm{C}$ \\
\hline 4 & $"$ & 13.5 & Continuously swim out & " & " & $"$ & $"$ \\
\hline 5 & $"$ & 14.2 & " & $"$ & $"$ & " & $"$ \\
\hline 6 & $" \prime$ & 19.6 & 15 sec. remain 2 ind. & $"$ & " & $"$ & " \\
\hline 7 & May 18 & 16.2 & Continuously swim out & $" \prime$ & $"$ & $"$ & $" \prime$ \\
\hline 8 & " & 17.8 & $14 \mathrm{cec}$. remain 1 ind. & $"$ & 20.2 & $\mathbf{L}$ & B \\
\hline 9 & $"$ & 18.5 & 13 sec. remain 1 ind. & "I & $"$ & $"$ & $"$ \\
\hline 10 & $"$ & 14.5 & 8 sec. remain 1 ind. & $"$ & $"$ & $\prime \prime$ & $" \prime$ \\
\hline
\end{tabular}

Experiment 2. 1 hour keeping inside cylinder

\begin{tabular}{|c|c|c|c|c|c|c|c|}
\hline 1 & May 16 & 13.0 & Continuously swim out & 15 & $18.6^{\circ} \mathrm{C}$ & $\mathrm{S}$ & A \\
\hline 2 & " & 45 & " & $"$ & $"$ & $\mathbf{M}$ & $\mathrm{C}$ \\
\hline 3 & $"$ & 75 & $40 \mathrm{sec}$. remain 1 ind. & $"$ & $" \prime$ & $"$ & $\Rightarrow$ \\
\hline 4 & $"$ & 38 & Continuously swim out & $"$ & $"$ & $"$ & $"$ \\
\hline 5 & May 17 & 20 & " & $"$ & 19.5 & $"$ & $"$ \\
\hline 6 & June 2 & 52 & $39 \mathrm{sec}$. remain 1 ind. & $n$ & 20.8 & $\mathbf{L}$ & $\mathrm{E}$ \\
\hline 7 & " & 38 & 24 sec. remain 2 ind. & $" \prime$ & 21.5 & $\Rightarrow$ & $"$ \\
\hline 8 & $"$ & 78 & $60 \mathrm{sec}$. remain 1 ind. & $"$ & 21.7 & $"$ & 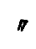 \\
\hline 9 & $"$ & 68 & $" \quad 3$ ind. & $"$ & 22.0 & $" \prime$ & , \\
\hline 10 & $"$ & 34 & Continuously swim out & $\Rightarrow$ & 22.3 & $\Rightarrow$ & , \\
\hline
\end{tabular}


Table 4. The result on the case using the white painted cylinder.

Experiment 3. 1 minute keeping inside cylinder

\begin{tabular}{|c|c|c|c|c|c|c|c|}
\hline \multicolumn{2}{|c|}{ Observation } & \multicolumn{2}{|c|}{ Time lapse swim out from the place } & \multirow{2}{*}{$\begin{array}{c}\text { Individual } \\
\text { number } \\
\text { used }\end{array}$} & \multirow{2}{*}{$\begin{array}{c}\text { Water } \\
\text { temperature }\end{array}$} & \multirow{2}{*}{$\begin{array}{c}\text { Materials } \\
\text { used }\end{array}$} & \multirow{2}{*}{$\begin{array}{l}\text { Tank } \\
\text { used }\end{array}$} \\
\hline Number & Date & $\begin{array}{c}\text { All } \\
\text { individuals }\end{array}$ & Remarks & & & & \\
\hline 1 & May 16 & $\begin{array}{l}\text { seconds } \\
8.0\end{array}$ & Continuously swim out & 15 & 20.9 & $\mathrm{~S}$ & A \\
\hline 2 & " & 13.0 & 9 sec. remain 1 ind. & $" \prime$ & $"$ & M & $\mathrm{C}$ \\
\hline 3 & " & 39.2 & 8 sec. remain 2 ind. & $"$ & $"$ & $"$ & $"$ \\
\hline 4 & " & 8.2 & Continuously swim out & $"$ & $" \prime$ & $" 1$ & $"$ \\
\hline 5 & 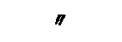 & 8.5 & " & 14 & " & $"$ & $"$ \\
\hline 6 & May 18 & 9.2 & $8 \mathrm{sec}$. remain 1 ind. & 10 & $"$ & $" \prime$ & $"$ \\
\hline 7 & $"$ & 10.9 & Continuously swim out & 15 & 20.2 & $\mathbf{L}$ & $B$ \\
\hline 8 & $"$ & 9.1 & " & $"$ & $"$ & $" \prime$ & $"$ \\
\hline 9 & 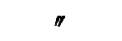 & 7.5 & $n$ & " & $"$ & $"$ & $"$ \\
\hline 10 & 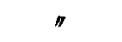 & 7.7 & $" \prime$ & " & $"$ & $"$ & $"$ \\
\hline 11 & $\Rightarrow$ & 17.9 & $8 \mathrm{sec}$. remain 2 ind. & $"$ & $"$ & $"$ & $"$ \\
\hline
\end{tabular}

Experiment 4. 1 hour keeping inside cylinder

\begin{tabular}{|c|c|c|c|c|c|c|c|}
\hline 1 & May 18 & 7.0 & Continuously swim out & 15 & $20.2^{\circ} \mathrm{C}$ & $\mathrm{M}$ & $\mathrm{C}$ \\
\hline 2 & " & 4.2 & $"$ & $"$ & $"$ & $" \prime$ & $" \prime$ \\
\hline 3 & " & 16.9 & $7 \mathrm{sec}$. remain 2 ind. & $"$ & 20.0 & $\mathrm{~L}$ & $\mathrm{~B}$ \\
\hline 4 & " & 6.2 & $4 \mathrm{sec}$. remain 2 ind. & $"$ & $"$ & $"$ & " \\
\hline 5 & 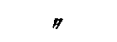 & 8.5 & $6 \mathrm{sec}$. remain 1 ind. & $"$ & " & $" \prime$ & $"$ \\
\hline 6 & May 19 & 18.3 & 14 sec. remain 1 ind. & " & 18.3 & $\mathbf{M}$ & $\mathrm{C}$ \\
\hline 7 & $\Rightarrow$ & 26.9 & 10 sec. remain 1 ind. & $"$ & $"$ & $" \prime$ & $"$ \\
\hline 8 & $"$ & 19.8 & 11 sec. remain 2 ind. & $"$ & " & " & $\prime \prime$ \\
\hline 9 & " & 13.7 & 8 sec. remain 1 ind. & $y$ & 18.1 & $" \prime$ & " \\
\hline 10 & $n$ & 66.0 & 30 sec. remain 3 ind. & $"$ & 18.5 & $" \prime$ & $n$ \\
\hline
\end{tabular}

Table 5. Comparism of keeping time and staying time with both types of cylinders.

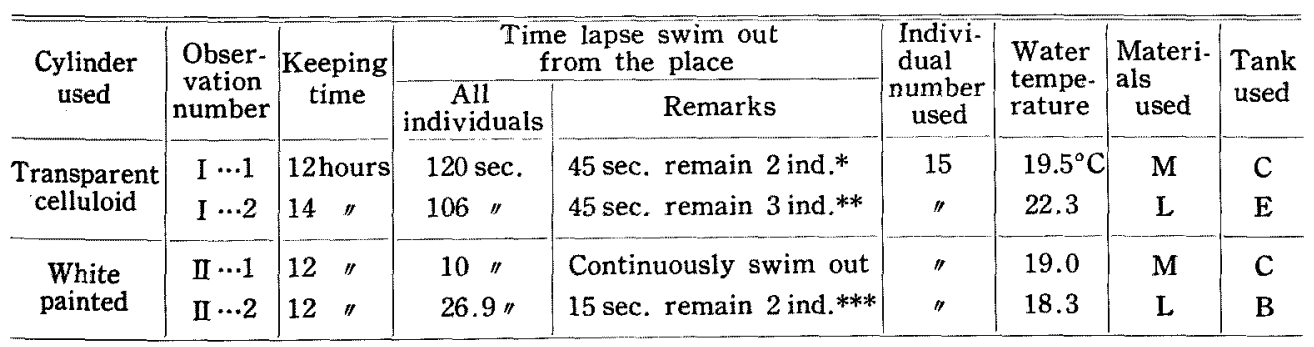

* Staying many seconds after once swam out and returned.

** Not very far away from the original place.

*** Many individuals return to the same place once swam out.

実験 5. 透明円筒叔よび白色円筒に約 12 時間留置してから開放した場合

結果は Table 5．に示したよ 5に透明円筒では白色円简の場合上りも円外に泳ぎ出す時間が著しく長く，

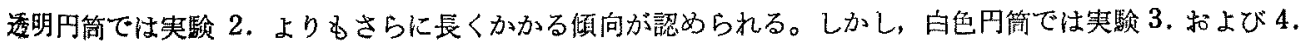


より幾分長いが，著しい差はないようであるが，実験の絽返し回数が少ないので断定できない。

考察

この实駼は逃避の反応行動と条件づけを含告問題を报かつていると考光られ，透明なセルロイド円简を使 用した場合に，白色の不透明な円简を使用した場合よりるメダカ群が円筒に閉じこめられていた場所から涾 ぎ去るまでに要する時間が長くかかる。この事柄に説明を与兄てみると, 透明円筒の場合, 停滞する時間が 長くなることは，透明円筒を識別することがやがてその限られた区域に魚を条件つけて，容器が除かれてる 漸次その影響が残つて，メがカがその場所が泳ざ出すのを抑制することに因ると考兄る。直接的訓楝化よる 条件つけけ影響であることは, 留置時間が長くなるほど, 停滞時間が長くなることから当然考えられる。白 色円筒の場合，停滞時間が短かいことは遮蔽物を除去したこと自体が，透明な円筒を除去するょりる魚仗 きな影響を与兄る。すなわち，周囲の突然の変化が著しいのは白色丹简であるという一つの見方ができる。 また，魚の逃避反応が透明円简ではその環境に条件づけられることによつて抑制されるのに対し，白色円简 を除去主る場合はむしろ刺激する方向に働らくのであるという別の考光方もできる。白色円简の場合の逃避 反応の現われ方の強さについて考光てみると，実験の結果では円筒の透明か否かにかかわらず，留膡された

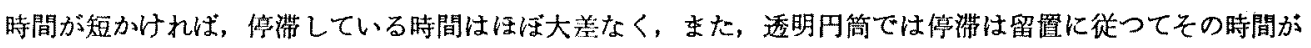
長くなり, 魚群の行動に修正が加わるのに, 白色円筒では留䁌時間に関係なく停滞は常に短時間で, 修正の 現象は認められない。要するに，この観察実呀で示された現象は魚群の逃避行動とこれを抑制する条件らけ の影暗とによつて説明できるものであると考觉る。

本文を䅂るにあたり, 御指道と御鞭達を睗つた東京大学教授大帛泰崔, 检山義夫両博士に深甚の謝意を表 する。

\section{引用 文 献}

1) Triplett, N. B.: (1901) The educability of the perch. Am. Journ. Psychol., Vol. 12, p. 354.

2) Russell, E.S. : (1931) Detour experiments with Stickle backs. Jour. Exper. Biol,, Vol. 8 , No. 4.

3) Spooner, G. M. : (1937) Learning of detours by wrass. Jour. Mar. Biol. Assoc. U. K. Vol. 21, No. 2 . 